\title{
Validation of Methods for Computational Catalyst Design: Geometries, Structures, and Energies of Neutral and Charged Silver Clusters
}

\author{
Kaining Duanmu and Donald G. Truhlar* \\ Department of Chemistry, Chemical Theory Center, Inorganometallic Catalyst Design Center, and Supercomputing Institute, \\ University of Minnesota, 207 Pleasant Street Southeast, Minneapolis, Minnesota 55455-0431, United States
}

\section{Supporting Information}

ABSTRACT: We report a systematic study of small silver clusters, $\mathrm{Ag}_{n}, \mathrm{Ag}_{n}{ }^{+}$, and $\mathrm{Ag}_{n}{ }^{-}$, $n=1-7$. We studied all possible isomers of clusters with $n=5-7$. We tested 42 exchange-correlation functionals, and we assess these functionals for their accuracy in three respects: geometries (quantitative prediction of internuclear distances), structures (the nature of the lowest-energy structure, for example, whether it is planar or nonplanar), and energies. We find that the ingredients of exchange-correlation functionals are indicators of their success in predicting geometries and structures: local exchange-correlation functionals are generally better than hybrid functionals for geometries; functionals depending on kinetic energy density are the best for predicting the lowest-energy isomer correctly, especially for predicting two-dimensional to threedimenstional transitions correctly. The accuracy for energies is less sensitive to the ingredient list. Our findings could be useful for guiding the selection of methods for computational catalyst design.

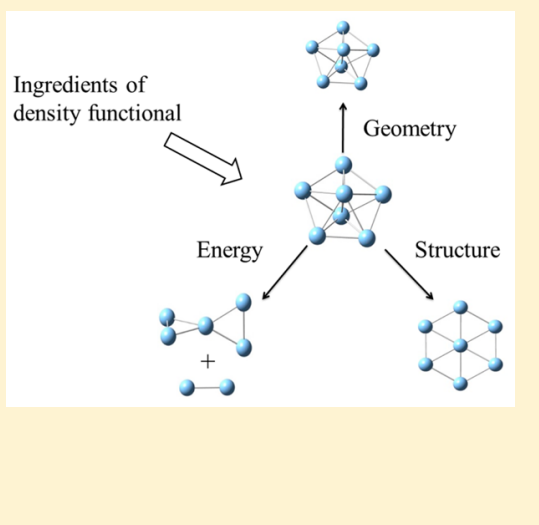

\section{INTRODUCTION}

Metal clusters and nanoparticles are important in chemistry and materials science because of their unique properties that are different from those of bulk materials. ${ }^{1-3}$ Silver clusters and nanoparticles are of special interest for their roles in photography ${ }^{4}$ and catalysis, ${ }^{5,6}$ and a variety of experimental techniques $^{7-17}$ and quantum mechanical computations ${ }^{18-32}$ have been used to study the properties of silver clusters.

Cluster properties vary significantly with size and structure, ${ }^{1,3,5,7-13,15,17,33-35}$ which is one reason why they are so interesting. To understand the properties of silver clusters, we need to study both geometrical and electronic structures. One theoretical method widely used for studying silver clusters is Kohn-Sham density functional theory, ${ }^{36}$ although its accuracy for metal clusters is less well validated than its accuracy for many other properties. Kohn-Sham theory would be exact if the exact exchange-correlation (xc) functional were known and were used; however, the exact $x c$ functional is unknown and essentially unknowable. Therefore, one must use approximate $\mathrm{xc}$ functionals, and this necessity leads to questions: Which, if any, of the xc functionals are reliable for metal clusters? Which of them give the most accurate results for geometries, structures, and energies of metal clusters? The answers are important in the short term for guiding choices of functionals for applications and in the long term for designing better density functionals. A particularly noteworthy previous study of this question is the work on neutral Ag clusters by Chen et al.; ${ }^{30}$ among many interesting results, they found that of six exchange-correlation functionals studied, the TPSS and M06 exchange-correlation functionals agree best with CCSD-
( $\mathrm{T}$ ) wave function calculations for the relative energies of $\mathrm{Ag}_{7}$ and $\mathrm{Ag}_{8}$.

In recent decades, a number of new xc functionals have been developed. Our group tested xc functionals against reliable experimental data for $3 \mathrm{~d}$ and $4 \mathrm{~d}$ transition metal atoms, ions, and compounds. ${ }^{37-39}$ In the present work, we choose a few of the more successful and more popular xc functionals from the literature and assess their reliability for small silver clusters in three respects: (1) geometries, (2) structures, and (3) energies. (1) Geometries determined from experiments are limited to $\mathrm{Ag}_{2}$ and $\mathrm{Ag}_{2}{ }^{-16,18}$ On the basis of available validation tests, ${ }^{20,22,23}$ we chose coupled cluster theory with single and double excitations and quasiperturbative connected triple excitations $(\operatorname{CCSD}(\mathrm{T}))^{40}$ to optimize the structures of isomers of $\mathrm{Ag}_{2-4}, \mathrm{Ag}_{2-4}{ }^{+}$, and $\mathrm{Ag}_{2-3}-$. We used data from experiments and $\operatorname{CCSD}(\mathrm{T})$ calculations as reference data to assess the $\mathrm{xc}$ functionals in terms of the mean unsigned error of bond lengths. (2) Structures of small silver clusters are wellestablished. For example, the structure of silver trimer is a Jahn-Teller-distorted $C_{2 v}$ obtuse isosceles triangle, and the structure of silver tetramer is a $C_{2 h}$ rhombus. Joint theoretical and experimental investigations ${ }^{7,8,15}$ identified the lowestenergy isomers for $\mathrm{Ag}_{n}, \mathrm{Ag}_{n}^{+}$, and $\mathrm{Ag}_{n}{ }^{-}(3 \leq n \leq 7)$ clusters. We performed a systematic search for these cluster sizes to find not only the lowest-energy isomers but also all possible isomers, and then we tested which of the xc functionals are able

Received: February 14, 2015

Revised: April 4, 2015

Published: April 7, 2015 
to predict the lowest-energy isomers correctly. (3) Experimental values are available for dissociation energies of $\mathrm{Ag}_{n}{ }^{+}$and $\mathrm{Ag}_{n}{ }^{-}(n=2-7),{ }^{11,12}$ vertical ionization potentials of $\mathrm{Ag}_{1-7}{ }^{13}$ and vertical detachment energies of $\mathrm{Ag}_{1-7}-{ }^{-15}$ We calculated all these types of energies with each $\mathrm{xc}$ functional and then compared them to the reference data from the experiments and to our $\operatorname{CCSD}(\mathrm{T})$ calculations on small neutral clusters.

\section{COMPUTATIONAL DETAILS}

In our calculations, all silver clusters are in the lowest possible spin states (singlets and doublets) except for the $D_{3 h}$ structure of $\mathrm{Ag}_{3}{ }^{-}$, which is in triplet spin state.

2.1. Test of Method for Generating Reference Data. For reference data, we used $\operatorname{CCSD}(\mathrm{T})$, as explained in section 1. All of our $\operatorname{CCSD}(\mathrm{T})$ calculations are carried out with the Molpro software package. ${ }^{41,42}$

Peterson and Puzzarini ${ }^{20}$ developed pseudopotential correlation-consistent polarized valence basis sets (cc-pVnZ-PP, $n=$ $\mathrm{D}, \mathrm{T}, \mathrm{Q}, 5$ ), diffuse-function-augmented versions (aug-ccpVnZ-PP, $n=\mathrm{D}, \mathrm{T}, \mathrm{Q}, 5)$ of these basis sets, and polarized outer-core and valence versions (cc-pwCVnZ-PP, $n=\mathrm{D}, \mathrm{T}, \mathrm{Q}$ 5 ). For silver, these are based on small-core (28 electrons replaced by pseudopotential) relativistic pseudopotentials. ${ }^{43}$ Peterson and Puzzarini ${ }^{20}$ and Huang and Watts ${ }^{23}$ did $\operatorname{CCSD}(\mathrm{T})$ calculations for $\mathrm{Ag}_{2}$ and $\mathrm{Ag}_{2}{ }^{-}$, respectively, with polarized valence basis sets and a correction $(\Delta \mathrm{CV})$ for corevalence correlation as the lowering in energy when upgrading the calculation to a polarized outer-core and valence basis set (i.e., in the notation below, from $\mathrm{pV}$ to $\mathrm{pwCV}$ ). Table 1 shows

Table 1. $\operatorname{CCSD}(\mathrm{T})$ Calculated Internuclear Distances (Angstroms) of $\mathrm{Ag}_{2}$ and $\mathrm{Ag}_{2}{ }^{-}$

\begin{tabular}{llll}
\multirow{4}{*}{ only valence polarization } & \multicolumn{1}{c}{ basis set } & $\mathrm{Ag}_{2}{ }^{a}$ & $\mathrm{Ag}_{2}{ }^{-b}$ \\
& aug-cc-pVDZ-PP & 2.5675 & 2.6995 \\
& aug-cc-pVTZ-PP & 2.5454 & 2.6701 \\
& aug-cc-pVQZ-PP & 2.5377 & 2.6616 \\
& aug-cc-pV5Z-PP & 2.5339 & \\
$\Delta \mathrm{CV}$ & cc-pwCVDZ-PP & -0.0113 & -0.0171 \\
& cc-pwCVTZ-PP & -0.0110 & -0.0148 \\
& cc-pwCVQZ-PP & -0.0113 & \\
$\Delta$ SO & cc-pwCV5Z-PP & -0.0111 & \\
exptl. ${ }^{c}$ & aug-cc-pVTZ-PP & -0.0012 & \\
${ }^{c}$ & & 2.5303 & $2.654 \pm 0.007$
\end{tabular}

${ }^{a}$ Ref 20. ${ }^{b} \operatorname{Ref} 23 .{ }^{c} \operatorname{Refs} 16$ and 17 . In ref 17 , the internuclear distance of $\mathrm{Ag}_{2}{ }^{-}$was determined to be $r_{\mathrm{e}}^{\prime}+0.124 \pm 0.007 \AA$, where $r_{\mathrm{e}}^{\prime}$ is the internuclear distance of $\mathrm{Ag}_{2}$. The reference paper used an uncertain assignment $r_{\mathrm{e}}^{\prime}=2.480 \AA$. Here, we substitute $r_{\mathrm{e}}^{\prime}$ with the more accurate value $2.5303 \AA$ and get the internuclear distance of $2.654 \pm 0.007 \AA$ for $\mathrm{Ag}_{2}{ }^{-}$.

the results (from the literature as indicated in the table, although we did repeat all the calcuations) of $\operatorname{CCSD}(\mathrm{T})$ geometry optimizations with various basis sets on $\mathrm{Ag}_{2}$ and $\mathrm{Ag}_{2}{ }^{-}$, indicating that the aug-cc-pVQZ-PP basis set gives converged geometries at the polarized valence level, and ccpwCVDZ-PP is already converged for the effect of $\Delta \mathrm{CV}$ on geometry.

Spin-orbit (SO) interaction was also calculated by Peterson and Puzzarini using internally contracted multireference configuration interaction (MR-CISD) calculations ${ }^{44}$ with augcc-pVTZ-PP basis set for $\mathrm{Ag}_{2}$, and the results in Table 1 indicate that the effect of $\mathrm{SO}$ coupling decreases the equilibrium interatomic distance $\left(r_{e}\right)$ but only by $0.001 \AA^{20}$ Therefore, we did not include SO interaction in the rest of our calculations.

2.2. Reference Data. As a result of the tests detailed in section 2.1, we used the aug-cc-pVQZ-PP basis set in our polarized valence $\operatorname{CCSD}(\mathrm{T})$ calculations and the cc-pwCVDZPP basis set to calculate the core-valence correlation effect.

2.3. Density Functional Calculations. The exchangecorrelation functionals studied in this article ${ }^{36,45-84}$ are listed in Table 2, where they are classified in terms of their type. The simplest form of $\mathrm{xc}$ functional is a local-spin-density approximation (LSDA), which is dependent only on spin-up and spin-down electron densities $\left(\rho_{\sigma}, \sigma=\alpha, \beta\right)$. A more general form of the xc functional is the generalized gradient approximation (GGA), which is dependent on $\rho_{\sigma}$ and its gradient $\nabla \rho_{\sigma}$, approximates density functional exchange (which includes static correlation) and dynamical correlation separately, and therefore has a separable form for exchange. If the density functional approximation depends only on these same ingredients but with a nonseparable form, it is called nonseparable gradient approximation (NGA). If the $\mathrm{xc}$ functional is also dependent on kinetic energy densities $\left(\tau_{\sigma}\right)$, it is called a meta-GGA or meta-NGA. If a meta-GGA employs a different treatment of the short-range and long-range regions of interelectronic separation, it is called a range-separated (RS) meta-GGA. In all the types mentioned so far, the functional depends on local values of the independent variables; such functionals are called local. Including nonlocal dependencies yields a hybrid functional. If a constant percentage of HartreeFock exchange is used, the functional is called a global-hybrid functional; if the short-range and long-range regions of interelectronic separation are treated by mixing different percentages of Hartree-Fock exchange with local exchange, the functional is called a range-separated hybrid functional.

In our Kohn-Sham calculations, we used a basis set that involves a small-core relativistic pseudopotential. ${ }^{43}$ We tested correlation-consistent basis sets ((aug)-cc-p(wC)VnZ-PP $))^{20}$ as well as efficient diffuse-function-augmented basis sets, prefixed with maug, may, and jun as explained previously. ${ }^{86,87}$ We found that Kohn-Sham calculations are not very sensitive to core functions in basis sets but are relatively more sensitive to diffuse functions. Considering both accuracy and cost, we finally chose the jun-cc-pVTZ-PP basis set. We use pruned grids with 99 radical shells and 590 angular points per shell (keyword "ultrafine" in Gaussian 09). All Kohn-Sham calculations are carried out with a locally modified version, MNGFM-6.4, of Gaussian 09. .8,89 $^{\text {. }}$

2.4. Structure Searching. To systematically study $\mathrm{Ag}_{5-7}$ clusters, we use the coalescence kick algorithm ${ }^{90}$ to systematically search for all possible isomers of each size of cluster. This method randomly generates a large number of structures by generating and pushing atoms from random directions toward the center; then, these structures are optimized to the nearest local minima or saddle point structures using the Kohn-Sham method. We first search for structures of neutral clusters, and then we use them as starting structures to further search for cationic and anionic structures. In our studies of neutral and charged silver clusters, we found that N12 is very good for geometries, with a mean unsigned error of bond length of only $0.009 \AA$, so we used N12 in all the searches. For all clusters with one imaginary frequency (saddle point structures), we also perform minimum energy path calculations to find their 
Table 2. Tested xc Functionals

\begin{tabular}{|c|c|c|c|c|c|}
\hline type & functional & refs & type & functional & refs \\
\hline LSDA & GVWN3 & $36,45,46$ & global-hybrid GGA & B97-1 & 47 \\
\hline \multirow[t]{11}{*}{ GGA } & BLYP & 48,49 & & B97-3 & 50 \\
\hline & BP86 & 48,51 & & B3PW91 & 52 \\
\hline & MOHLYP & 53 & & BHandH & 54 \\
\hline & mPWLYP & 49,55 & & BHandHLYP & 54 \\
\hline & mPWPW91 & 55,56 & & MPWLYP1M & 53 \\
\hline & OreLYP & $49,57,58$ & & MPW3LYP & 59 \\
\hline & PBE & 60 & & O3LYP & 61 \\
\hline & PBEsol & 62 & & PBE0 & 63 \\
\hline & PW91 & 56 & & SOGGA11-X & 64 \\
\hline & RPBE & 65 & global-hybrid meta-GGA & BMK & 66 \\
\hline & SOGGA & 67 & & M05 & 68 \\
\hline NGA & $\mathrm{N} 12$ & 69 & & M06 & 70 \\
\hline \multirow[t]{4}{*}{ meta-GGA } & M06-L & 71 & & TPSSh & 72 \\
\hline & TPSS & 73 & & TPSS1KCIS & $72,74,75$ \\
\hline & revTPSS & 75 & & $\tau$-HCTHhyb & 76 \\
\hline & $\tau$-HCTH & 76 & range-separated hybrid GGA & CAM-B3LYP & 77 \\
\hline RS meta-GGA & M11-L & 78 & & HSE06 & 79,80 \\
\hline meta-NGA & MN12-L & 81 & range-separated hybrid meta-GGA & M11 & 82 \\
\hline \multirow[t]{2}{*}{ global-hybrid GGA } & B1LYP & 83 & range-separated hybrid NGA & N12-SX & 84 \\
\hline & B3LYP & 85 & range-separated hybrid meta-GGA & MN12-SX & 84 \\
\hline
\end{tabular}

connections to local minima. The results are shown in Supporting Information (Figures S2-S10).

\section{RESULTS AND DISCUSSION}

First we test the accuracy of $\mathrm{xc}$ functionals for geometries. Internuclear distances of $\mathrm{Ag}_{2}$ and $\mathrm{Ag}_{2}{ }^{-}$have been determined

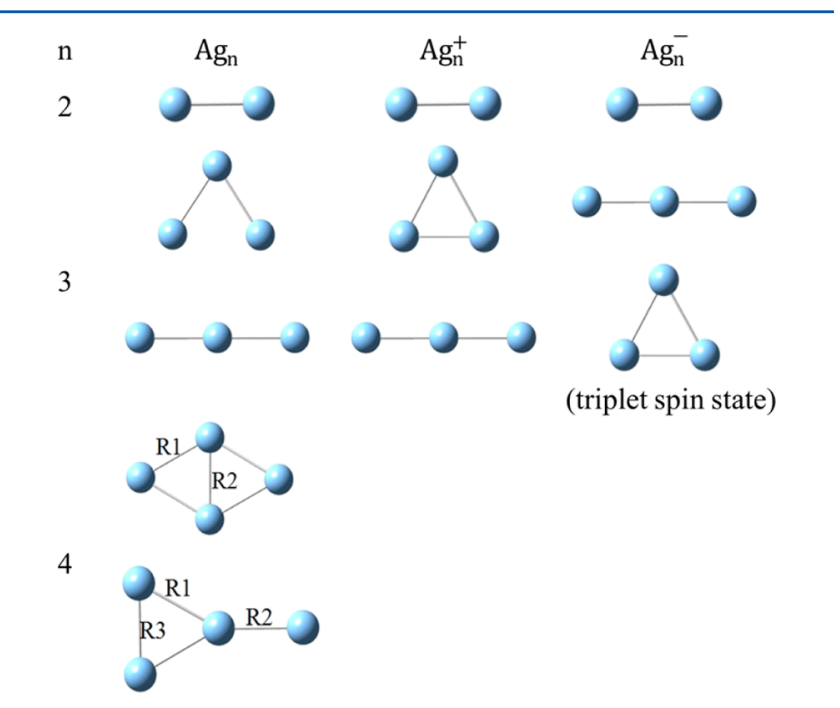

Figure 1. Neutral and charged silver clusters used in geometry studies.

from spectroscopy experiments. ${ }^{16,17}$ We use $\operatorname{CCSD}(\mathrm{T}) /$ aug-ccpVQZ-PP plus core-valence correlation functions $(\mathrm{CCSD}(\mathrm{T}) /$ cc-pwCVDZ-PP) method to optimize the lowest-energy isomers of $\mathrm{Ag}_{2}{ }^{+}, \mathrm{Ag}_{3}, \mathrm{Ag}_{3}{ }^{+}, \mathrm{Ag}_{3}{ }^{-}, \mathrm{Ag}_{4}$, as well as other isomers: a $D_{\infty h}$ structure of $\mathrm{Ag}_{3}$, a $D_{\infty h}$ structure of $\mathrm{Ag}_{3}{ }^{+}$, a $D_{3 h}$ structure of $\mathrm{Ag}_{3}{ }^{-}$, and a $C_{2 v}$ structure of $\mathrm{Ag}_{4}$. Figure 1 shows the structures of 11 neutral and charged silver clusters used as reference data for geometries. Because the $D_{2 h}$ structure of $\mathrm{Ag}_{4}$ has two different bond lengths, the $C_{2 v}$ structure of $\mathrm{Ag}_{4}$ has three different bond lengths, and each of the other structures has one unique bond length, there are 14 bond lengths in total.
We optimized these structures using the Kohn-Sham method with $42 \mathrm{xc}$ functionals in Table 2, and we compare the 14 bond lengths with reference data from experiments and $\operatorname{CCSD}(\mathrm{T})$ calculations.

We note that the structure of $\mathrm{Ag}_{3}$ is not an equilateral triangle because of the Jahn-Teller effect. Previous work predicted that the structure has $C_{2 v}$ symmetry with a bond angle between 65 and 80 degrees, ${ }^{31,32}$ and we found that most of our density functional theory (DFT) calculations agree with that prediction. The accuracy of xc functionals for geometry in terms of mean unsigned error of bond length is shown in Table 3 along with the percentage of Hartree-Fock exchange. We can see that although there are fewer local functionals than hybrid functionals in the test set (19 local functionals and 23 hybrid functionals), 7 out of the 10 best performing functionals are local functionals, and the two best performing functionals, TPSS and N12, are both local functionals. Only 3 of the 10 best functionals are hybrid functionals, and two of these have relatively low percentages of Hartree-Fock exchange, in particular $10 \%$ and $15 \%$. We conclude that including Hartree-Fock exchange in xc functionals does not generally improve the geometry predictions for silver clusters, and this is consistent with our experience on other metals.

Next we examine how well the xc functionals are able to predict the correct structures. There is more than one isomer for each silver cluster containing more than two atoms, so it is important to see if the xc functionals are able to correctly predict the lowest-energy isomer for each cluster. The lowestenergy isomers of neutral, cationic, and anionic silver clusters can be ascertained from previous experiments and theoretical studies. For neutral clusters, optical absorption was measured experimentally and also calculated with time-dependent density functional theory; ${ }^{7}$ the comparison of experiment to the calculations identified the lowest-energy isomers for $n=3-7$. For cationic clusters, collision cross sections were measured from ion mobility experiments and compared with results calculated by Kohn-Sham calculations ${ }^{8}$ so that the lowestenergy isomers of $\mathrm{Ag}_{3-7}{ }^{+}$clusters were identified. For anionic 
Table 3. Percentage of Hartree-Fock Exchange and Mean Unsigned Error (MUE) of 14 Bond Lengths for Each xc Functional ${ }^{a}$

\begin{tabular}{lllllc}
\multicolumn{1}{c}{ functional } & \multicolumn{1}{c}{$X^{b}$} & MUE of bond length $(\AA)$ & functional & $X^{b}$ & MUE of bond length $(\AA)$ \\
TPSS & 0 & 0.008 & M06-L & 0 & 0.044 \\
N12 & 0 & 0.009 & HSE06 & $25-0$ & 0.047 \\
BHandH & 50 & 0.009 & M11-L & 0 & 0.059 \\
revTPSS & 0 & 0.013 & mPW3LYP & 21.8 & 0.063 \\
TPSSh & 10 & 0.015 & mPWLYP & 0 & 0.064 \\
BP86 & 0 & 0.021 & M06 & 27 & 0.064 \\
PW91 & 0 & 0.021 & B3LYP & 20 & 0.066 \\
MN12-L & 0 & 0.025 & MPWLYP1M & 5 & 0.066 \\
PBE & 0 & 0.027 & B97-1 & 21 & 0.067 \\
$\tau$-HCTHhyb & 15 & 0.028 & BLYP & 0 & 0.072 \\
PBEsol & 0 & 0.028 & RPBE & 0 & 0.074 \\
MN12-SX & $0-25$ & 0.032 & GVWN3 & 0 & 0.075 \\
SOGGA & 0 & 0.033 & B1LYP & 25 & 0.076 \\
$\tau$-HCTH & 0 & 0.035 & SOGGA11-X & 35.42 & 0.079 \\
M11 & $42.8-100$ & 0.036 & BMK & 42 & 0.080 \\
mPWPW91 & 0 & 0.036 & OreLYP & 0 & 0.081 \\
N12-SX & $25-0$ & 0.037 & O3LYP & 11.61 & 0.085 \\
CAM-B3LYP & $19-65$ & 0.037 & BHandHLYP & 50 & 0.086 \\
B3PW91 & 20 & 0.038 & B97-3 & 26.93 & 0.106 \\
PBE0 & 25 & 0.038 & M05 & 28 & 0.109 \\
TPSS1KCIS & 13 & 0.041 & MOHLYP & 0 & 0.116 \\
${ }^{a}$ Listed in order of increasing MUE before rounding. & $b$ Percentage of Hartree-Fock exchange. &
\end{tabular}

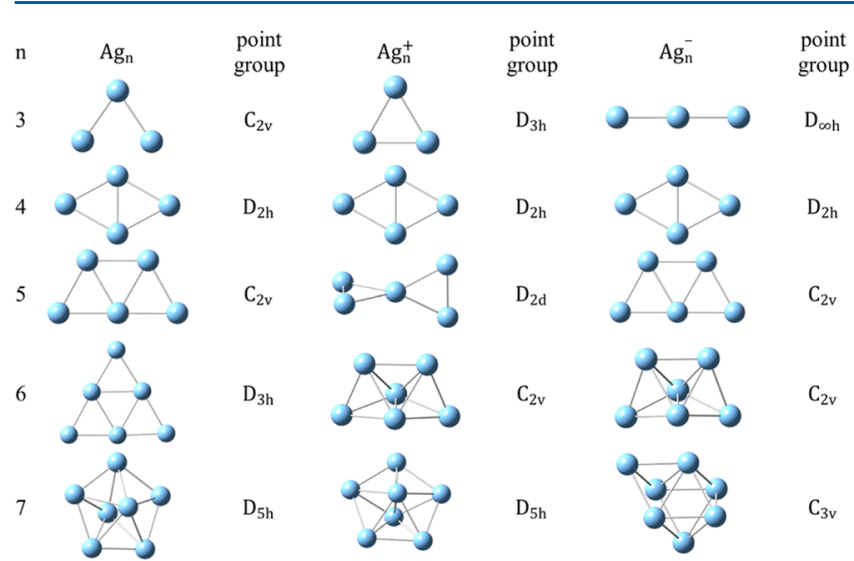

Figure 2. Lowest-energy isomers for neutral and charged $\operatorname{Ag}_{n}(n=3-$ 7).

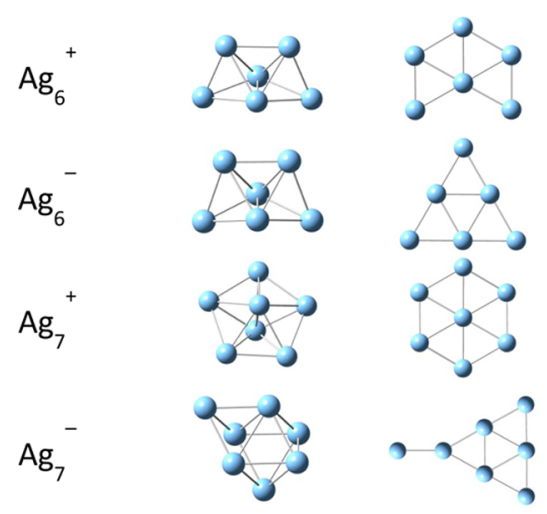

Figure 3. $3 \mathrm{D}$ and $2 \mathrm{D}$ silver clusters. The structure on the left is the lowest-energy $3 \mathrm{D}$ structure, and the one on the right is a competing low-energy $2 \mathrm{D}$ structure.

clusters, transition energies were measured from photoelectron spectra experiments ${ }^{15}$ and were compared to theoretical calculations; ${ }^{91}$ the main spectra peaks agree well for particular $\mathrm{Ag}_{3-7}{ }^{-}$clusters, which were therefore judged to be the lowestenergy isomers for each size of anionic silver clusters. Therefore, the determination of all the clusters are based on the comparison of one feature measured from experiments and calculated from computations. One common feature of the findings is that for all neutral, cationic, and anionic silver clusters with $n \leq 7$, one predominant isomer could be identified for each size of cluster; with $n>7$, there might be more than one isomer coexisting so that the feature measured from experiments (such as optical absorption spectrum, collision cross section, or photoelectron spectrum) cannot be attributed to only one isomer; thus, the lowest-energy isomers cannot be identified in this way for higher $n$.

The lowest-energy isomers for neutral and charged $\operatorname{Ag}_{n}(n=$ $3-7)$ are shown in Figure 2. As we mentioned before, there is more than one isomer for each size of cluster. For example, we find that there are at least 10 other local minimum structures for $\mathrm{Ag}_{7}$. Therefore, we take some low-energy local minima structures optimized with the N12 functional, and we calculate the electronic energies with various $\mathrm{xc}$ functionals to see which of them are able to correctly predict the lowest-energy structures. Detailed information is shown in the Supporting Information (Table S3).

There are 15 lowest-energy isomers for neutral and charged $\operatorname{Ag}_{n}(n=3-7)$ determined as described above, and we tested 42 exchange-correlation functionals, so we have a total of 630 theoretical predictions of the lowest-energy isomers, and we find that 121 of the 630 predictions are incorrect. First question will be which structures are most likely to be predicted incorrectly. We find that the wrong predictions mainly occur for $\mathrm{Ag}_{6}{ }^{+}, \mathrm{Ag}_{6}{ }^{-}, \mathrm{Ag}_{7}{ }^{+}$, and $\mathrm{Ag}_{7}{ }^{-}$; there are 82 wrong predictions for these four clusters, which is $68 \%$ of the total number of wrong predictions. A key point here is that for all these four cases there is a close competition between two-dimensional (2D) and three-dimensional (3D) structures: the four lowestenergy isomers are three-dimensional structures, but all the 
Table 4. Number of Wrong Predictions (out of 15) of the Lowest-Energy Isomer and the Dependence on Kinetic Energy Density for Each xc Functional

\begin{tabular}{|c|c|c|c|c|c|}
\hline functional & $\begin{array}{l}\text { dependence on kinetic energy } \\
\text { density }\end{array}$ & $\begin{array}{c}\text { number of wrong } \\
\text { predictions }\end{array}$ & functional & $\begin{array}{l}\text { dependence on kinetic energy } \\
\text { density }\end{array}$ & $\begin{array}{c}\text { number of wrong } \\
\text { predictions }\end{array}$ \\
\hline BHandH & no & 0 & mPWPW91 & no & 3 \\
\hline M05 & yes & 0 & M11 & yes & 3 \\
\hline M06 & yes & 0 & PBE & no & 3 \\
\hline M06-L & yes & 0 & PW91 & no & 3 \\
\hline MN12-L & yes & 0 & CAM-B3LYP & no & 4 \\
\hline MN12-SX & yes & 0 & SOGGA11-X & no & 4 \\
\hline PBE0 & no & 0 & $\tau$-HCTHhyb & yes & 5 \\
\hline PBEsol & no & 0 & $\tau$-НСТН & yes & 5 \\
\hline revTPSS & yes & 0 & mPW3LYP & no & 5 \\
\hline SOGGA & no & 0 & $\mathrm{RPBE}$ & no & 5 \\
\hline TPSS & yes & 0 & B97-1 & no & 5 \\
\hline TPSS1KCIS & yes & 0 & BHandHLYP & no & 5 \\
\hline TPSSh & yes & 0 & mPWLYP & no & 6 \\
\hline BMK & yes & 1 & mPWLYP1M & no & 6 \\
\hline GVWN3 & no & 1 & OreLYP & no & 6 \\
\hline HSE06 & no & 1 & O3LYP & no & 6 \\
\hline M11-L & yes & 1 & B97-3 & no & 6 \\
\hline N12-SX & no & 1 & BLYP & no & 7 \\
\hline N12 & no & 2 & B3LYP & no & 7 \\
\hline BP86 & no & 3 & B1LYP & no & 7 \\
\hline B3PW91 & no & 3 & MOHLYP & no & 7 \\
\hline
\end{tabular}

Table 5. Energies (Kilocalories per Mole) for Neutral and Charged Silver Clusters

\begin{tabular}{|c|c|c|c|c|}
\hline & M06 & $\operatorname{CCSD}(\mathrm{T})$ & $\begin{array}{l}\text { exptl. } \\
\left(D_{0}\right)^{a}\end{array}$ & $\begin{array}{l}\text { exptl. } \\
\left(D_{\mathrm{e}}\right)^{b}\end{array}$ \\
\hline $\mathrm{Ag}_{2} \rightarrow 2 \mathrm{Ag}$ & 42.6 & 39.4 & & 38.0 \\
\hline $\mathrm{C}_{2 v}-\mathrm{Ag}_{3} \rightarrow \mathrm{Ag}_{2}+\mathrm{Ag}$ & 21.6 & 20.8 & & \\
\hline $\mathrm{C}_{2 v}-\mathrm{Ag}_{3} \rightarrow 3 \mathrm{Ag}$ & 64.2 & 60.2 & & 60.7 \\
\hline$C_{2 v}-\mathrm{Ag}_{3} \rightarrow D_{\infty h}-\mathrm{Ag}_{3}$ & 1.5 & 3.9 & & \\
\hline$D_{2 h}-\mathrm{Ag}_{4} \rightarrow \mathrm{C}_{2 v}-\mathrm{Ag}_{3}+\mathrm{Ag}$ & 49.5 & 50.3 & & \\
\hline$D_{2 h}-\mathrm{Ag}_{4} \rightarrow 2 \mathrm{Ag}_{2}$ & 28.4 & 31.6 & & \\
\hline$D_{2 h}-\mathrm{Ag}_{4} \rightarrow 4 \mathrm{Ag}$ & 113.7 & 110.5 & & \\
\hline$D_{2 h}-\mathrm{Ag}_{4} \rightarrow C_{2 v}-\mathrm{Ag}_{4}$ & 5.6 & 7.9 & & \\
\hline $\mathrm{Ag}_{2}^{+} \rightarrow \mathrm{Ag}+\mathrm{Ag}^{+}$ & 38.6 & 37.6 & 40.1 & 40.3 \\
\hline $\mathrm{Ag}_{3}^{+} \rightarrow \mathrm{Ag}_{2}+\mathrm{Ag}^{+}$ & 64.7 & 67.6 & 62.3 & 62.7 \\
\hline $\mathrm{Ag}_{4}^{+} \rightarrow \mathrm{Ag}+\mathrm{Ag}_{3}^{+}$ & 29.8 & & 24.2 & 24.5 \\
\hline $\mathrm{Ag}_{5}{ }^{+} \rightarrow \mathrm{Ag}_{2}+\mathrm{Ag}_{3}{ }^{+}$ & 39.7 & & 45.4 & 45.8 \\
\hline $\mathrm{Ag}_{6}^{+} \rightarrow \mathrm{Ag}+\mathrm{Ag}_{5}^{+}$ & 37.1 & & 29.5 & 30.0 \\
\hline $\mathrm{Ag}_{7}^{+} \rightarrow \mathrm{Ag}_{2}+\mathrm{Ag}_{5}^{+}$ & 57.0 & & 52.1 & 52.8 \\
\hline $\mathrm{Ag}_{2}^{-} \rightarrow \mathrm{Ag}+\mathrm{Ag}^{-}$ & 33.7 & 33.0 & 42.2 & 42.4 \\
\hline $\mathrm{Ag}_{3}^{-} \rightarrow \mathrm{Ag}+\mathrm{Ag}_{2}^{-}$ & 52.5 & 50.1 & 55.6 & 55.9 \\
\hline $\mathrm{Ag}_{3}^{-} \rightarrow \mathrm{Ag}_{2}+\mathrm{Ag}^{-}$ & 43.5 & 43.7 & 48.7 & 49.0 \\
\hline $\mathrm{Ag}_{4}{ }^{-} \rightarrow \mathrm{Ag}+\mathrm{Ag}_{3}{ }^{-}$ & 33.4 & & 31.4 & 31.8 \\
\hline $\mathrm{Ag}_{4}^{-} \rightarrow \mathrm{Ag}_{2}+\mathrm{Ag}_{2}^{-}$ & 43.3 & & 38.1 & 38.5 \\
\hline $\mathrm{Ag}_{5}^{-} \rightarrow \mathrm{Ag}+\mathrm{Ag}_{4}^{-}$ & 50.4 & & 44.7 & 45.1 \\
\hline $\mathrm{Ag}_{5}{ }^{-} \rightarrow \mathrm{Ag}_{2}+\mathrm{Ag}_{3}{ }^{-}$ & 41.2 & & 41.3 & 41.8 \\
\hline $\mathrm{Ag}_{6}^{-} \rightarrow \mathrm{Ag}+\mathrm{Ag}_{5}^{-}$ & 40.3 & & 43.6 & 44.1 \\
\hline $\mathrm{Ag}_{6}^{-} \rightarrow \mathrm{Ag}_{2}+\mathrm{Ag}_{4}^{-}$ & 48.1 & & 40.6 & 41.2 \\
\hline $\mathrm{Ag}_{7}^{-} \rightarrow \mathrm{Ag}+\mathrm{Ag}_{6}^{-}$ & 60.1 & & 63.0 & 63.5 \\
\hline $\mathrm{Ag}_{7}^{-} \rightarrow \mathrm{Ag}_{2}+\mathrm{Ag}_{5}^{-}$ & 57.8 & & 64.6 & 65.4 \\
\hline
\end{tabular}

${ }^{a}$ The dissociation energies $\left(D_{0}\right)$ are from refs 11 and $12 .{ }^{b}$ The dissociation energies of $\mathrm{Ag}_{2}$ and $\mathrm{Ag}_{3}$ are from refs 16 and 18, respectively. The dissociation energies $\left(D_{\mathrm{e}}\right)$ of cationic and anionic clusters are calculated by removing the effect of the zero-point vibrational energy on $D_{0}$.
Table 6. Adiabatic IPs and DEs and Vertical IPs and DEs (Kilocalories per Mole) of Silver Clusters Calculated by M06

\begin{tabular}{lccclccc} 
& $\mathrm{AIP}$ & $\mathrm{VIP}$ & $\begin{array}{c}\text { exptl. } \\
\mathrm{VIP}^{13}\end{array}$ & & $\mathrm{ADE}$ & $\mathrm{VDE}$ & $\begin{array}{c}\text { exptl. } \\
\text { VDE }\end{array}$ \\
$\mathrm{Ag}$ & 175.4 & 175.4 & 174.6 & $\mathrm{Ag}^{-}$ & 34.1 & 34.1 & 30.0 \\
$\mathrm{Ag}_{2}$ & 179.5 & 180.7 & 175.3 & $\mathrm{Ag}_{2}{ }^{-}$ & 25.2 & 26.6 & 25.4 \\
$\mathrm{Ag}_{3}$ & 132.3 & 135.5 & 143.0 & $\mathrm{Ag}_{3}{ }^{-}$ & 56.1 & 57.7 & 56.0 \\
$\mathrm{Ag}_{4}$ & 152.0 & 152.2 & 153.4 & $\mathrm{Ag}_{4}{ }^{-}$ & 40.0 & 42.0 & 37.6 \\
$\mathrm{Ag}_{5}$ & 138.1 & 143.5 & 146.4 & $\mathrm{Ag}_{5}{ }^{-}$ & 51.9 & 51.9 & 48.9 \\
$\mathrm{Ag}_{6}$ & 157.0 & 166.6 & 164.9 & $\mathrm{Ag}_{6}{ }^{-}$ & 36.1 & 51.0 & 48.0 \\
$\mathrm{Ag}_{7}$ & 137.0 & 140.4 & 147.6 & $\mathrm{Ag}_{7}{ }^{-}$ & 53.8 & 63.9 & 60.0 \\
\hline
\end{tabular}

wrong predictions yield planar two-dimensional structures as the lowest-energy isomers. Figure 3 shows the 3D lowestenergy isomers of $\mathrm{Ag}_{6}{ }^{+}, \mathrm{Ag}_{6}{ }^{-}, \mathrm{Ag}_{7}{ }^{+}$, and $\mathrm{Ag}_{7}{ }^{-}$, as well as the $2 \mathrm{D}$ competing low-energy isomers.

The first 13 entries of Table 4 are the functionals that are able to predict all the lowest-energy isomers correctly. In the full set of xc functionals that we tested, 14 depend on kinetic energy density and 28 do not, while 9 out of the 14 functionals that depend on kinetic energy density are exact for all structures, which suggests kinetic energy density makes the xc functionals more likely to be correct for predicting lowestenergy isomers. Similar findings were reported in previous work on gold clusters; in particular, Mantina et al., ${ }^{92}$ Johansson et al., ${ }^{93}$ and Ferrighi et al. ${ }^{94}$ studied the 2D-to-3D structural transitions (as functions of $n$ ) for singly charged gold clusters $\mathrm{Au}_{n}{ }^{+}$and $\mathrm{Ag}_{n}{ }^{-}$, and in this context Ferrighi et al. provided an analysis of the connection of the kinetic energy density dependence to predictions of the $3 \mathrm{D}-2 \mathrm{D}$ competition. The gold clusters tend to be planar structures at small size but to be compact $3 \mathrm{D}$ structures at large size. Experiments indicate that $n$ $=8$ for $\mathrm{Au}_{n}{ }^{+}$and $n=12$ for $\mathrm{Au}_{n}{ }^{-}$are the sizes where the 2D-to$3 \mathrm{D}$ transitions take place. Computational studies revealed that xc functionals with kinetic density dependence are more successful in predicting the correct transitions because the 
Table 7. Mean Unsigned Error for Each Energetic Quantity (Kilocalories per Mole) ${ }^{a}$

\begin{tabular}{|c|c|c|c|c|c|c|c|c|c|}
\hline functional & neutral & dissociation & VIP & VDE & functional & neutral & dissociation & VIP & VDE \\
\hline M06 & 2.6 & 4.6 & 3.8 & 3.1 & mPW3LYP & 7.4 & 9.3 & 4.8 & 1.1 \\
\hline PBE & 2.5 & 5.0 & 5.0 & 1.6 & SOGGA & 6.9 & 9.6 & 5.1 & 1.0 \\
\hline BMK & 3.4 & 4.8 & 5.3 & 1.2 & CAM-B3LYP & 7.7 & 8.3 & 5.9 & 2.7 \\
\hline$\tau$-HCTHhyb & 4.8 & 4.6 & 5.0 & 1.5 & MN12-SX & 8.7 & 5.2 & 10.4 & 5.4 \\
\hline PW91 & 2.7 & 5.0 & 5.6 & 2.7 & mPWLYP & 5.5 & 8.9 & 8.2 & 2.4 \\
\hline TPSS & 1.9 & 5.5 & 5.9 & 2.4 & mPWLYP1M & 6.1 & 9.2 & 7.5 & 1.5 \\
\hline mPWPW91 & 3.3 & 5.0 & 5.0 & 4.3 & RPBE & 8.2 & 9.6 & 5.3 & 1.5 \\
\hline TPSSh & 2.5 & 5.1 & 6.5 & 4.1 & M05 & 4.8 & 7.4 & 10.5 & 5.4 \\
\hline $\mathrm{N} 12$ & 3.1 & 5.0 & 6.8 & 3.9 & B3LYP & 8.6 & 10.4 & 4.6 & 1.2 \\
\hline HSE06 & 4.6 & 4.9 & 5.6 & 4.7 & M11-L & 7.5 & 8.2 & 11.5 & 1.9 \\
\hline BP86 & 3.0 & 4.9 & 6.6 & 5.2 & BLYP & 6.9 & 10.3 & 7.6 & 5.2 \\
\hline PBE0 & 5.3 & 5.2 & 6.2 & 3.5 & MN12-L & 9.8 & 11.5 & 4.3 & 4.3 \\
\hline revTPSS & 3.7 & 7.6 & 5.6 & 1.9 & B97-3 & 8.6 & 11.9 & 6.9 & 4.1 \\
\hline N12-SX & 4.3 & 4.9 & 7.6 & 5.4 & B1LYP & 10.2 & 12.2 & 5.9 & 3.2 \\
\hline SOGGA11-X & 5.0 & 7.1 & 5.3 & 1.1 & B97-1 & 4.2 & 14.1 & 6.2 & 8.1 \\
\hline TPSS1KCIS & 5.7 & 5.6 & 6.7 & 4.4 & OreLYP & 12.1 & 16.0 & 7.9 & 3.7 \\
\hline B3PW91 & 7.1 & 6.8 & 5.4 & 2.1 & BHandHLYP & 12.4 & 13.6 & 10.5 & 7.6 \\
\hline M06-L & 4.1 & 7.6 & 7.7 & 2.5 & M11 & 8.6 & 8.4 & 20.0 & 18.4 \\
\hline BHandH & 1.5 & 6.0 & 9.7 & 7.9 & O3LYP & 13.8 & 16.4 & 8.1 & 6.1 \\
\hline PBEsol & 6.5 & 8.4 & 5.8 & 1.9 & MOHLYP & 15.0 & 19.5 & 8.2 & 5.8 \\
\hline$\tau$-НСТН & 5.4 & 8.6 & 6.6 & 1.7 & GVWN3 & 16.4 & 17.7 & 20.8 & 17.8 \\
\hline
\end{tabular}

Table 8. Total Mean Unsigned Error of Energy (Kilocalories per Mole) for Each xc Functional ${ }^{a}$

\begin{tabular}{|c|c|c|c|c|c|c|c|}
\hline functional & $X^{b}$ & dependence on $\tau_{\sigma}{ }^{c}$ & MUE of energy & functional & $X$ & dependence on $\tau_{\sigma}$ & MUE of energy \\
\hline M06 & 27 & yes & 3.8 & mPW3LYP & 0 & no & 6.6 \\
\hline PBE & 0 & no & 3.9 & SOGGA & 0 & no & 6.7 \\
\hline BMK & 42 & yes & 4.0 & CAM-B3LYP & $19-65$ & no & 6.7 \\
\hline$\tau$-HCTHhyb & 15 & yes & 4.2 & MN12-SX & $0-25$ & yes & 6.9 \\
\hline PW91 & 0 & no & 4.2 & mPWLYP & 0 & no & 6.9 \\
\hline TPSS & 0 & yes & 4.3 & mPWLYP1M & 5 & no & 6.9 \\
\hline mPWPW91 & 0 & no & 4.5 & RPBE & 0 & no & 7.1 \\
\hline TPSSh & 10 & yes & 4.7 & M05 & 28 & yes & 7.1 \\
\hline $\mathrm{N} 12$ & 0 & no & 4.7 & B3LYP & 20 & no & 7.3 \\
\hline HSE06 & $25-0^{d}$ & no & 4.9 & M11-L & 0 & yes & 7.5 \\
\hline BP86 & 0 & no & 4.9 & BLYP & 0 & no & 8.2 \\
\hline PBE0 & 25 & no & 5.1 & MN12-L & 0 & yes & 8.6 \\
\hline revTPSS & 0 & yes & 5.3 & B97-3 & 26.93 & no & 8.9 \\
\hline N12-SX & $25-0$ & no & 5.3 & B1LYP & 25 & no & 9.0 \\
\hline SOGGA11-X & 35.42 & no & 5.4 & B97-1 & 21 & no & 9.5 \\
\hline TPSS1KCIS & 13 & yes & 5.6 & OreLYP & 0 & no & 11.5 \\
\hline B3PW91 & 20 & no & 5.7 & BHandHLYP & 50 & no & 11.7 \\
\hline M06-L & 0 & yes & 6.0 & M11 & $42.8-100$ & yes & 12.3 \\
\hline BHandH & 50 & no & 6.1 & O3LYP & 11.61 & no & 12.5 \\
\hline PBEsol & 0 & no & 6.4 & MOHLYP & 0 & no & 14.1 \\
\hline$\tau$-НСТН & 0 & yes & 6.4 & GVWN3 & 0 & no & 18.0 \\
\hline
\end{tabular}

${ }^{a}$ Listed in order of increasing MUE before rounding. ${ }^{b}$ Percentage of Hartree-Fock exchange. ${ }^{c}$ Kinetic energy density. ${ }^{d}$ When a range of $X$ is given, the first value is for small interelectronic separation and the second is for large interelectronic separation.

kinetic energy density favors the compact 3D structures. In our studies for silver, which is in the same column of the periodic table as gold, $n=5$ and $n=6$ are the sizes where the $2 \mathrm{D}$-to-3D transitions occur for $\mathrm{Ag}_{n}^{+}$and $\mathrm{Ag}_{n}{ }^{-}$, respectively, and $\mathrm{xc}$ functionals dependent on kinetic energy density are more likely to correctly predict the lowest-energy isomers near the transitions.

Finally, we studied the reliability of the density functionals for reaction energies. These reaction energies are categorized as reaction energies of the neutral clusters $\left(\mathrm{Ag}_{1-4}\right)$, dissociation energies of cationic and anionic silver clusters $\left(\mathrm{Ag}_{n}{ }^{+}\right.$and $\mathrm{Ag}_{n}{ }^{-}, n$ $=2-7)$, vertical ionization potentials $\left(\mathrm{Ag}_{1-7}\right)$, and vertical detachment energies $\left(\mathrm{Ag}_{1-7}^{-}\right)$.

We use $\operatorname{CCSD}(\mathrm{T})$ calculations as the reference data for the reaction energies of the neutral clusters. A multiple-collision induced dissociation (MCID) experiment was carried out for cationic silver clusters, ${ }^{11}$ and further analysis of the experimental data generated the dissociation energies of singly charged cationic silver clusters $\mathrm{Ag}_{n}{ }^{+}$. The fragmentation channels of singly charged cationic silver clusters have also 
been studied. ${ }^{10,11}$ In the case of $\mathrm{Ag}_{n}^{+}(n=2-7)$ clusters, a single fragmentation channel is found almost exclusively for each cluster: even-numbered clusters decay by emission of a silver monomer, while odd-numbered clusters decay by emission of a silver dimer. Therefore, we can consider the dissociation energies are exclusively monomer-loss reaction energies for even-numbered clusters $\left(\mathrm{Ag}_{n}{ }^{+} \rightarrow \mathrm{Ag}+\mathrm{Ag}_{n-1}{ }^{+}, n=\right.$ even number) and dimer-loss reaction energies for oddnumbered clusters $\left(\mathrm{Ag}_{n}{ }^{+} \rightarrow \mathrm{Ag}_{2}+\mathrm{Ag}_{n-2}{ }^{+}, n=\right.$ odd number $)$. Collision-induced dissociation (CID) experiments were performed on anionic silver clusters. ${ }^{12}$ Similarly to what found for cationic silver clusters, the predominant fragmentation channel is atom-loss for even-numbered anionic clusters and dimer-loss for odd-numbered anionic clusters, and a fitting scheme based on single-channel thresholds is used for calculating the energies. However, the atom-loss fragmentation channel is not negligible for odd-numbered anionic clusters, so another scheme involving competitive CID threshold fits was used in the paper to calculate the dissociation energies of oddnumbered anionic clusters through two fragmentation channels. We take the dissociation energies of single-channel threshold fits for even-numbered clusters and competitive CID threshold fits for odd-numbered clusters as our reference data, and finally we use experimentally measured monomer-loss dissociation energies for even-numbered silver anions $\left(\mathrm{Ag}_{n}{ }^{-} \rightarrow \mathrm{Ag}+\right.$ $\mathrm{Ag}_{n-1}{ }^{-}, n=$ even number) and both monomer-loss and dimerloss dissociation energies for odd-numbered silver anions $\left(\mathrm{Ag}_{n}{ }^{-}\right.$ $\rightarrow \mathrm{Ag}+\mathrm{Ag}_{n-1}{ }^{-}$, and $\mathrm{Ag}_{n}{ }^{-} \rightarrow \mathrm{Ag}_{2}+\mathrm{Ag}_{n-2}{ }^{-}, n=$ odd number) as reference data. Dissociation energies from experiments $\left(D_{0}\right)$ include the effect of zero-point energy (ZPE). To compare our calculations with experiments, we calculate zero-point energies with the N12 exchange-correlation functional and subtract that from the experimental data to get $D_{\mathrm{e}}$. Vertical ionization potentials (VIPs) and vertical detachment energies (VDEs) of silver clusters were also measured. ${ }^{13-15}$ With the known lowestenergy isomers in Figure 1, we calculated the VIPs and VDEs of the $\mathrm{Ag}_{1-7}$ clusters. There are 39 reaction energies of all the types mentioned above; details are provided in Supporting Information (Tables S4-S8).

Tables 5 and 6 show the best theoretically calculated energies of neutral clusters, dissociation energies of charged clusters, VIPs, and VDEs. We also show DFT-calculated adiabatic ionization potentials (AIPs) and adiabatic detachment energies (ADEs) in Table 6 because those are more directly relevant to the experiments. Experimental results are provided where available.

We summarize the mean unsigned error (MUE) for each energetic quantity in Table 7 . The table shows that different functionals are preferred for various energetic quantities. In particular, BHandH, TPSS, and PBE are the best for the energies of neutral clusters; M06, $\tau$-HCTHhyb, and BMK are the best for the dissociation energies of cationic and anionic silver clusters; M06, MN12-L, and B3LYP are the best for VIP; and SOGGA, SOGGA11-X, and mPW3LYP are the best for VDE.

We summarize the total MUE and the ingredients of the functionals in Table 8 . The best functionals in total are M06, PBE, and BMK. For these functionals the number of wrong structure predictions (from Table 4) is zero for M06, three for PBE, and one for BMK. Table 8 shows that the accuracy of a functional for energies is not mainly dependent on the percentage of Hartree-Fock exchange or the inclusion of kinetic energy density. In the top 10 functionals, half of them are hybrid functionals and half of them are local functionals, and half of them are meta-functionals and half of them have no kinetic energy density dependence.

It is interesting to compare the conclusions from the validation tests summarized in Table 8 to those from the study of the relative energies of $\mathrm{Ag}_{7}$ and $\mathrm{Ag}_{8}$ clusters by Chen et al. ${ }^{30}$ They found that M06 and TPSS were more accurate than B3LYP, PBE, and PW91. Our broader study again ranks M06 and TPSS highly and downgrades B3LYP, but we also find good average performance for PBE and PW91.

\section{CONCLUSIONS}

Neutral and singly charged small silver clusters $\left(\mathrm{Ag}_{n}, \mathrm{Ag}_{n}{ }^{+}\right.$, and $\left.\mathrm{Ag}_{n}{ }^{-}, n=1-7\right)$ have been studied. We systematically searched for all possible isomers of clusters with $n=5-7$. We assessed the reliability of $42 \mathrm{xc}$ functionals in terms of structures, geometries, and energies. We found that local functionals are generally more reliable for geometries; 7 out of 10 best performing functionals for geometries are local functionals, and the best 3 are TPSS (which is local), N12 (also local), and $\mathrm{BHandH}$ (which is nonlocal). We also found that functionals that depend on kinetic energy density are more likely to predict accurate structures. In our study, 9 out of the 14 exchangecorrelation functionals that include kinetic energy density predict all 15 structures for $n=3-7$ correctly, whereas only 4 of the 28 exchange-correlation functionals that do not include kinetic energy density predict them all correctly. Energies are categorized as reaction energies of neutral $\mathrm{Ag}_{1-4}$ clusters, dissociation energies of cationic and anionic silver clusters $\left(\mathrm{Ag}_{n}{ }^{+}\right.$and $\left.\mathrm{Ag}_{n}^{-}, n=2-7\right)$, vertical ionization potentials $\left(\mathrm{Ag}_{1-7}\right)$, and vertical detachment energies $\left(\mathrm{Ag}_{1-7}{ }^{-}\right)$. The best functionals for the totality of energetic quantities are M06, PBE, and BMK. The accuracy for energies is not much affected by which ingredients are included in functionals. These findings could be useful for guiding the choice of methods for computational catalyst design.

\section{ASSOCIATED CONTENT}

\section{S Supporting Information}

Structures and bond lengths for the study of geometry; structures searched by coalescence kick algorithm; all types of reaction energies. This material is available free of charge via the Internet at http://pubs.acs.org.

\section{AUTHOR INFORMATION}

\section{Corresponding Author}

*E-mail: truhlar@umn.edu.

\section{Notes}

The authors declare no competing financial interest.

\section{ACKNOWLEDGMENTS}

The authors are grateful to Boris Averkiev for providing the coalescence kick program and to Run $\mathrm{Li}$ for early stage exploratory calculations on Ag clusters. This work was supported in part by the Inorganometallic Catalyst Design Center, an Energy Frontier Research Center funded by the U.S. Department of Energy, Office of Science, Basic Energy Sciences under Award DE-SC0012702. This research was performed in part using the computing resources of the MSCF in EMSL, a national scientific user facility sponsored by the U.S. DOE, Office of Basic Energy Research and located at PNNL and also 
using the computing resources of Minnesota Supercomputing Institute.

\section{REFERENCES}

(1) Baletto, F.; Ferrando, R. Structural Properties of Nanoclusters: Energetic, Thermodynamic, and Kinetic Effects. Rev. Mod. Phys. 2005, 77, 371-423.

(2) Perepichka, D. F.; Federico, R. Metal Nanoparticles: From "Artificial Atoms" to "Artificial Molecules". Angew. Chem., Int. Ed. 2007, 46, 6006-6008.

(3) Castro, T.; Reifenberger, R.; Choi, E.; Andres, R. P. SizeDependent Melting Temperature of Individual Nanometer-Sized Metallic Clusters. Phys. Rev. B: Condens. Matter Mater. Phys. 1990, 42, 8548-8556.

(4) Eachus, R. S.; Marchetti, A. P.; Muenter, A. A. The Photophysics of Silver Halide Imaging Materials. Annu. Rev. Phys. Chem. 1999, 50, 117-144.

(5) Koretsky, G. M.; Knickelbein, M. B. The Reactions of Silver Clusters with Ethylene and Ethylene Oxide: Infrared and Photoionization Studies of $\operatorname{Ag}_{n}\left(\mathrm{C}_{2} \mathrm{H}_{4}\right)_{m}, \mathrm{Ag}_{n}\left(\mathrm{C}_{2} \mathrm{H}_{4} \mathrm{O}\right)_{m}$ and Their Deuterated Analogs. J. Chem. Phys. 1997, 107, 10555-10566.

(6) Bernhardt, T. M. Gas-Phase Kinetics and Catalytic Reactions of Small Silver and Gold Clusters. Int. J. Mass Spectrom. 2005, 243, 1-29.

(7) Harb, M.; Rabilloud, F.; Simon, D.; Rydlo, A.; Lecoultre, S.; Conus, F.; Rodrigues, V.; Félix, C. Optical Absorption of Small Silver Clusters: $\operatorname{Ag}_{n}(n=4-22)$. J. Chem. Phys. 2008, 129, 194108-1194108-9.

(8) Weis, P.; Bierweiler, T.; Gilb, S.; Kappes, M. M. Structures of Small Silver Cluster Cations $\left(\mathrm{Ag}_{n}^{+}, n<12\right)$ : Ion Mobility Measurements versus Density Functional and MP2 Calculations. Chem. Phys. Lett. 2002, 355, 355-364.

(9) Blom, M. N.; Schooss, D.; Stairs, J.; Kappes, M. M. Experimental Structure Determination of Silver Cluster Ions $\left(\mathrm{Ag}_{n}^{+}, 19 \leq n \leq 79\right)$. J. Chem. Phys. 2006, 124, 244308-1-244308-10.

(10) Krückeberg, S.; Dietrich, G.; Lützenkirchen, K.; Schweikhard, L.; Walther, C.; Ziegler, J. The Dissociation Channels of Silver Clusters $\mathrm{Ag}_{n}^{+}, 3 \leq n \leq 20$. Int. J. Mass Spectrom. 1996, 155, 141-148.

(11) Krückeberg, S.; Dietrich, G.; Lützenkirchen, K.; Schweikhard, L.; Walther, C.; Ziegler, J. Multiple-Collision Induced Dissociation of Trapped Silver Clusters $\operatorname{Ag}_{n}^{+}(2 \leq n \leq 25)$. J. Chem. Phys. 1999, 110, $7216-7227$

(12) Spasov, V. A.; Lee, T. H.; Maberry, J. P.; Ervin, K. M. Measurement of the Dissociation Energies of Anionic Silver Clusters $\left(\mathrm{Ag}_{n}^{-} n=2-11\right)$ by Collision-Induced Dissociation. J. Chem. Phys. 1990, 110, 5208-5217.

(13) Jackschath, C.; Rabin, I.; Schulze, W. Electron Impact Ionization of Silver Clusters $\mathrm{Ag}_{n}, n \leq 36$. Z. Phys. D: At., Mol. Clusters 1992, 22, $517-520$.

(14) Alameddin, G.; Hunter, J.; Cameron, D.; Kappes, M. M. Electronic and Geometric Structure in Silver Clusters. Chem. Phys. Lett. 1992, 192, 122-128.

(15) Handschuh, H.; Cha, C.; Bechthold, P. S.; Ganteför, G.; Eberhardt, W. Electronic Shells or Molecular Orbitals: Photoelectron Spectra of $\mathrm{Ag}_{n}^{-}$Clusters. J. Chem. Phys. 1995, 102, 6406-6422.

(16) Beutel, V.; Krämer, H. G.; Bhale, G. L.; Kuhn, M.; Weyers, K.; Demtröder, W. High-Resolution Isotope Selective Laser Spectroscopy of $\mathrm{Ag}_{2}$ Molecules. J. Chem. Phys. 1993, 98, 2699-2708.

(17) Ho, J.; Ervin, K. M.; Lineberger, W. C. Photoelectron Spectroscopy of Metal Cluster Anions: $\mathrm{Cu}_{n}^{-}, \mathrm{Ag}_{n}^{-}, \mathrm{Au}_{n}^{-}$. J. Chem. Phys. 1990, 93, 6987-7002.

(18) Hilpert, K.; Gingerich, K. A. Atomization Enthalpies of Copper, Silver, and Gold Molecules $\mathrm{Cu}_{3}, \mathrm{Ag}_{3}$, and $\mathrm{Au}_{3}$. Ber. Bunsen.-Ges. 1980, 84, 739-745.

(19) Fournier, R. Theoretical Study of the Structure of Silver Clusters. J. Chem. Phys. 2001, 115, 2165-2177.

(20) Peterson, K. A.; Puzzarini, C. Systematically Convergent Basis Sets for Transition Metals. II. Pseudopotential-Based Correlation Consistent Basis Sets for the Group $11(\mathrm{Cu}, \mathrm{Ag}, \mathrm{Au})$ and $12(\mathrm{Zn}, \mathrm{Cd}$, Hg) Elements. Theor. Chem. Acc. 2005, 114, 283-296.
(21) Zhao, S.; Li, Z.; Wang, W.; Liu, Z.; Fan, K.; Xie, Y.; Schaefer, H. F., III. Is the Uniform Electron Gas Limit Important for Small Ag Clusters? Assessment of Different Density Functionals for $\mathrm{Ag}_{n}(n \leq 4)$. J. Chem. Phys. 2006, 124, 184102-1-184102-10.

(22) Yoon, J.; Kim, K. S.; Baeck, K. K. Ab initio Study of the LowLying Electronic States of $\mathrm{Ag}_{3}^{-}, \mathrm{Ag}_{3}$, and $\mathrm{Ag}_{3}^{+}$: A Coupled-Cluster Approach. J. Chem. Phys. 2000, 112, 9335-9342.

(23) Huang, M.; Watts, J. D. Theoretical Study of Triatomic Silver $\left(\mathrm{Ag}_{3}\right)$ and Its Ions with Coupled-Cluster Methods and CorrelationConsistent Basis Sets. Phys. Chem. Chem. Phys. 2012, 14, 6849-6855.

(24) Oviedo, J.; Palmer, R. E. Amorphous Structures of $\mathrm{Cu}, \mathrm{Ag}$, and $\mathrm{Au}$ Nanoclusters from First Principles Calculations. J. Chem. Phys. 2002, 117, 9548-9551.

(25) Yang, M.; Jackson, K. A.; Jellinek, J. First-Principles Study of Intermediate Size Silver Clusters: Shape Evolution and Its Impact on Cluster Properties. J. Chem. Phys. 2006, 125, 144308-1-144308-8.

(26) Alamanova, D.; Grigoryan, V. G.; Springborg, M. Theoretical Study of the Structure and Energetics of Silver Clusters. J. Phys.Chem. C 2007, 111, 12577-12587.

(27) Takesue, M.; Tomura, T.; Yamada, M.; Hata, K.; Kuwamoto, S.; Yonezawa, T. Size of Elementary Clusters and Process Period in Silver Nanoparticle Formation. J. Am. Chem. Soc. 2011, 133, 14164-14167.

(28) Duanmu, K.; Truhlar, D. G. Partial Ionic Character Beyond the Pauling Paradigm: Metal Nanoparticles. J. Phys. Chem. C 2014, 18, 28069-28074.

(29) Sierralta, A.; Arez, R.; Alejos, P. Performance of Density Functional Methods. Some Difficult Cases for Small Systems Containing $\mathrm{Cu}, \mathrm{Ag}$, or Au. J. Phys. Chem. A 2013, 117, 2619-2628.

(30) Chen, M.; Dyer, J. E.; Li, K.; Dixon, D. A. Prediction of Structures and Atomization Energies of Small Silver Clusters, $(\mathrm{Ag})_{n}, n$ < 100. J. Phys. Chem. A 2013, 117, 8298-8313.

(31) Richtsmeier, S. C.; Dixon, D. A.; Gole, J. L. The Theoretical Prediction of the Vibrational Spectra of Group IB Trimers. Proc. Natl. Acad. Sci. U.S.A. 1980, 77, 5611-5615. erratum: 1981, 78, 7259.

(32) Richtsmeier, S. C.; Eades, R. A.;Dixon, D. A.; Gole, J. L. The Electronic Structure of Small Group IA and Group IB Metal Clusters. In Metal Bonding and Interactions in High Temperature Systems; Gole, J. L., Stwalley, W. C., Eds.; A.C.S. Symposium Series; American Chemical Society: Washington, D.C., 1982; Vol. 179, pp 177-205.

(33) Yudanov, I. V.; Genest, A.; Schauermann, S.; Freund, H.-J.; Rösch, N. Size Dependence of the Adsorption Energy of CO on Metal Nanoparticles: A DFT Search for the Minimum Value. Nano Lett. 2012, 12, 2134-2139.

(34) Pei, Y.; Zeng, X. C. Investigating the Structural Evolution of Thiolate Protected Gold Clusters from First-Principles. Nanoscale 2012, 4, 4054-4072.

(35) Li, Z. H.; Truhlar, D. G. Nanothermodynamics of Metal Nanoparticles. Chem. Sci. 2014, 5, 2605-2624.

(36) Kohn, W.; Sham, L. J. Self-Consistent Equations Including Exchange and Correlation Effects. Phys. Rev. 1964, 140, A1133A1138.

(37) Zhang, W.; Truhlar, D. G.; Tang, M. Tests of ExchangeCorrelation Functional Approximations Against Reliable Experimental Data for Average Bond Energies of 3d Transition Metal Compounds. J. Chem. Theory Comput. 2013, 9, 3965-3977.

(38) Luo, S.; Truhlar, D. G. How Evenly Can Approximate Density Functionals Treat the Different Multiplicities and Ionization States of 4d Transition Metal Atoms? J. Chem. Theory Comput. 2012, 8, 41124126.

(39) Luo, S.; Averkiev, B.; Yang, K. R.; Xu, X.; Truhlar, D. G. Density Functional Theory of Open-Shell Systems. The 3d-Series Transition Metal Atoms and Their Cations. J. Chem. Theory Comput. 2014, 10, $102-121$.

(40) Raghavachari, K.; Trucks, G. W.; Pople, J. A.; Head-Gordon, M. A Fifth-Order Perturbation Comparison of Electron Correlation Theories. Chem. Phys. Lett. 1989, 157, 479-483.

(41) Werner, H.-J.; Knowles, P. J.; Knizia, G.; Manby, F. R.; Schütz, M. Molpro: A General-Purpose Quantum Chemistry Program Package. Wiley Interdiscip. Rev: Comput. Mol. Sci. 2012, 2, 242-253. 
(42) Werner, H.-J.; Knowles, P. J.; Knizia, G.; Manby, F. R.; Schütz, M.; Celani, P.; Korona, T.; Lindh, R.; Mitrushenkov, A.; Rauhut, G. et al. MOLPRO, version 2012.1, A Package of Ab Initio Programs, 2012

(43) Figgen, D.; Rauhut, G.; Dolg, M.; Stoll, H. Energy-Consistent Pseudopotentials for Group 11 and 12 Atoms: Adjustment to MultiConfiguration Dirac-Hartree-Fock Data. Chem. Phys. 2005, 311, 227-244.

(44) Werner, H.-J.; Knowles, P. J. An Efficient Internally Contracted Multiconfiguration-Reference Configuration Interaction Method. J. Chem. Phys. 1988, 89, 5803-5814.

(45) Gáspár, R. Statistical Exchange for Electron in Shell and the X $\alpha$ Method. Acta Phys. Acad. Sci. Hung. 1974, 35, 213-218.

(46) Vosko, S. H.; Wilk, L.; Nusair, M. Accurate Spin-Dependent Electron Liquid Correlation Energies for Local Spin Density Calculations: A Critical Analysis. Can. J. Phys. 1980, 58, 1200-1211.

(47) Hamprecht, F. A.; Cohen, A. J.; Tozer, D. J.; Handy, N. C. Development and Assessment of New Exchange-Correlation Functionals. J. Chem. Phys. 1998, 109, 6264-6271.

(48) Becke, A. D. Density-Functional Exchange-Energy Approximation with Correct Asymptotic-Behavior. Phys. Rev. A: At., Mol., Opt. Phys. 1988, 38, 3098-3100.

(49) Lee, C.; Yang, W.; Parr, R. G. Development of the Colle-Salvetti Correlation-Energy Formula into a Functional of the Electron Density. Phys. Rev. B: Condens. Matter Mater. Phys. 1988, 37, 785-789.

(50) Keal, T. W.; Tozer, D. J. Semiempirical Hybrid Functional with Improved Performance in an Extensive Chemical Assessment. J. Chem. Phys. 2005, 123, 121103-1-121103-4.

(51) Perdew, J. P. Density-Functional Approximation for the Correlation Energy of the Inhomogeneous Electron Gas. Phys. Rev. B: Condens. Matter Mater. Phys. 1986, 33, 8822-8824.

(52) Becke, A. D. Density-Functional Thermochemistry. III. The Role of Exact Exchange. J. Chem. Phys. 1993, 98, 5648-5652.

(53) Schultz, N. E.; Zhao, Y.; Truhlar, D. G. Density Functionals for Inorganometallic and Organometallic Chemistry. J. Phys. Chem. A 2005, 109, 11127-11143.

(54) Becke, A. D. A New Mixing of Hartree-Fock and Local DensityFunctional Theories. J. Chem. Phys. 1993, 98, 1372-1377.

(55) Adamo, C.; Barone, V. Exchange Functionals with Improved Long-Range Behavior and Adiabatic Connection Methods without Adjustable Parameters: The mPW and mPW1PW Models. J. Chem. Phys. 1998, 108, 664-675.

(56) Perdew, J. P. In Electronic Structure of Solids '91; Ziesche, P., Eschrig, H., Eds.; Akademie Verlag: Berlin, 1991; pp 11-20.

(57) Handy, N. C.; Cohen, A. J. Left-Right Correlation Energy. Mol. Phys. 2001, 99, 403-412.

(58) Thakkar, A. J.; McCarthy, S. P. Toward Improved Density Functionals for the Correlation Energy. J. Chem. Phys. 2009, 131, 134109-1-134109-12.

(59) Zhao, Y.; Truhlar, D. G. Hybrid Meta Density Functional Theory Methods for Thermochemistry, Thermochemical Kinetics, and Noncovalent Interactions: The MPW1B95 and MPWB1K Models and Comparative Assessments for Hydrogen Bonding and van der Waals Interactions. J. Phys. Chem. A 2004, 108, 6908-6918.

(60) Perdew, J. P.; Burke, K.; Ernzerhof, M. Generalized Gradient Approximation Made Simple. Phys. Rev. Lett. 1996, 77, 3865-3868.

(61) Hoe, W.-M.; Cohen, A. J.; Handy, N. C. Assessment of a New Local Exchange Functional OPTX. Chem. Phys. Lett. 2001, 341, 319328.

(62) Perdew, J. P.; Ruzsinszky, A.; Csonka, G. I.; Vydrov, O. A.; Scuseria, G. E.; Constantin, L. A.; Zhou, X.; Burke, K. Restoring the Density-Gradient Expansion for Exchange in Solids and Surfaces. Phys. Rev. Lett. 2008, 100, 136406-1-136406-4.

(63) Adamo, C.; Barone, V. Toward Reliable Density Functional Methods without Adjustable Parameters: The PBE0 model. J. Chem. Phys. 1999, 110, 6158-6170.

(64) Peverati, R.; Truhlar, D. G. A Global Hybrid Generalized Gradient Approximation to the Exchange-Correlation Functional that Satisfies the Second-Order Density-Gradient Constraint and has Broad
Applicability in Chemistry. J. Chem. Phys. 2011, 135, 191102-1191102-4.

(65) Hammer, B.; Hansen, L. B.; Norskov, J. K. Improved Adsorption Energetics within Density-Functional Theory Using Revised Perdew-Burke-Ernzerhof Functionals. Phys. Rev. B: Condens. Matter Mater. Phys. 1999, 59, 7413-7421.

(66) Boese, A. D.; Martin, J. M. L. Development of Density Functionals for Thermochemical Kinetics. J. Chem. Phys. 2004, 121, $3405-3416$

(67) Zhao, Y.; Truhlar, D. G. Construction of A Generalized Gradient Approximation by Restoring the Density-Gradient Expansion and Enforcing a Tight Lieb-Oxford Bound. J. Chem. Phys. 2008, 128, 184109-1-184109-8.

(68) Zhao, Y.; Schultz, N. E.; Truhlar, D. G. Exchange-Correlation Functional with Broad Accuracy for Metallic and Nonmetallic Compounds, Kinetics, and Noncovalent Interactions. J. Chem. Phys. 2005, 123, 161103-1-161103-4.

(69) Peverati, R.; Truhlar, D. G. Exchange-Correlation Functional with Good Accuracy for Both Structural and Energetic Properties while Depending Only on the Density and Its Gradient. J. Chem. Theory Comput. 2012, 8, 2310-2319.

(70) Zhao, Y.; Truhlar, D. G. The M06 Suite of Density Functionals for Main Group Thermochemistry, Thermochemical Kinetics, Noncovalent Interactions, Excited States, and Transition Elements: Two New Functionals and Systematic Testing of Four M06-Class Functionals and 12 Other Functionals. Theor. Chem. Acc. 2008, 120, $215-241$.

(71) Zhao, Y.; Truhlar, D. G. A New Local Density Functional for Main-Group Thermochemistry, Transition Metal Bonding, Thermochemical Kinetics, and Noncovalent Interactions. J. Chem. Phys. 2006, 125, 194101-1-194101-18.

(72) Staroverov, V. N.; Scuseria, G. E.; Tao, J.; Perdew, J. P. Comparative Assessment of A New Nonempirical Density Functional: Molecules and Hydrogen-Bonded Complexes. J. Chem. Phys. 2003, 119, 12129-12137.

(73) Tao, J.; Perdew, J. P.; Staroverov, V. N.; Scuseria, G. E. Climbing the Density Functional Ladder: Nonempirical Meta-Generalized Gradient Approximation Designed for Molecules and Solids. Phys. Rev. Lett. 2003, 91, 146401-1-146401-4.

(74) Krieger, J. B.; Chen, J.; Iafrate, G. J.; Savin, A. In Electron Correlations and Materials Properties; Gonis, A., Kioussis, N., Eds.; Plenum: New York, 1999; pp 463-477.

(75) Perdew, J. P.; Ruzsinszky, A.; Csonka, G. I.; Constantin, L. A.; Sun, J. Workhorse Semilocal Density Functional for Condensed Matter Physics and Quantum Chemistry. Phys. Rev. Lett. 2009, 103, 026403-1-026403-4.

(76) Boese, A. D.; Handy, N. C. New Exchange-Correlation Density Functionals: The Role of the Kinetic-Energy Density. J. Chem. Phys. 2002, 116, 9559-9569.

(77) Yanai, T.; Tew, D. P.; Handy, N. C. A New Hybrid ExchangeCorrelation Functional Using the Coulomb-Attenuating Method (CAM-B3LYP). Chem. Phys. Lett. 2004, 393, 51-57.

(78) Peverati, R.; Truhlar, D. G. M11-L: A Local Density Functional that Provides Improved Accuracy for Electronic Structure Calculations in Chemistry and Physics. J. Phys. Chem. Lett. 2011, 3, 117-124.

(79) Heyd, J.; Scuseria, G. E. Efficient Hybrid Density Functional Calculations in Solids: The HS-Ernzerhof Screened Coulomb Hybrid Functional. J. Chem. Phys. 2004, 121, 1187-1192.

(80) Henderson, T. M.; Izmaylov, A. F.; Scalmani, G.; Scuseria, G. E. Can Short-Range Hybrids Describe Long-Range-Dependent Properties? J. Chem. Phys. 2009, 131, 044108-1-044108-9.

(81) Peverati, R.; Truhlar, D. G. An Improved and Broadly Accurate Local Approximation to the Exchange-Correlation Density Functional: The MN12-L Functional for Electronic Structure Calculations in Chemistry and Physics. Phys. Chem. Chem. Phys. 2012, 14, 1317113174.

(82) Peverati, R.; Truhlar, D. G. Improving the Accuracy of Hybrid Meta-GGA Density Functionals by Range Separation. J. Phys. Chem. Lett. 2011, 2, 2810-2817. 
(83) Adamo, C.; Barone, V. Toward Reliable Adiabatic Connection Models Free from Adjustable Parameters. Chem. Phys. Lett. 1997, 274, 242-250.

(84) Peverati, R.; Truhlar, D. G. Screened-Exchange Density Functionals with Broad Accuracy for Chemistry and Solid State Physics. Phys. Chem. Chem. Phys. 2012, 14, 16187-16191.

(85) Stephens, P. J.; Devlin, F. J.; Chabalowski, C. F.; Frisch, M. J. Ab Initio Calculation of Vibrational Absorption and Circular Dichroism Spectra Using Density Functional Force Fields. J. Phys. Chem. 1994, 98, 11623-11627.

(86) Papajak, E.; Leverentz, H. R.; Zheng, J.; Truhlar, D. G. Efficient Diffuse Basis Sets: cc-pVxZ+ and maug-cc-pVxZ. J. Chem. Theory Comput. 2009, 5, 1197-1202.

(87) Papajak, E.; Truhlar, D. G. Efficient Diffuse Basis Sets for Density Functional Theory. J. Chem. Theory Comput. 2010, 6, 597601.

(88) Frisch, M. J.; Trucks, G. W.; Schlegel, H. B.; Scuseria, G. E.; Robb, M. A.; Cheeseman, J. R.; Scalmani, G.; Barone, V.; Mennucci, B.; Petersson, G. A. et al. Gaussian 09, revision C.01; Gaussian, Inc.: Wallingford CT, 2010.

(89) Zhao, Y.; Peverati, R.; Yang, K. R.; Truhlar, D. G. Minnesota Density Functionals Module 6.4, MN-GFM 6.4. http://comp.chem. umn.edu/mn-gfm/, Sep. 6, 2012.

(90) Averkiev, B. B. Geometry and Electronic Structure of Doped Clusters Via The Coalescence Kick Method; Ph.D. Dissertation, Utah State University, Logan, UT, 2009.

(91) Bonačić-Koutecký, V.; Češpiva, L.; Fantucci, P.; Pittner, J.; Koutecký, J. Effective Core Potential Configuration Interaction Study of Electronic Structure and Geometry of Small Anionic $\mathrm{Ag}_{n}$ Clusters: Predictions and Interpretation of Photodetachment Spectra. J. Chem. Phys. 1994, 100, 490-506.

(92) Mantina, M.; Valero, R.; Truhlar, D. G. Validation Study of the Ability of Density Functionals to Predict the Planar-to-ThreeDimensional Structural Transition in Anionic Gold Clusters. J. Chem. Phys. 2009, 131, 064706-1-064706-5.

(93) Johansson, M. P.; Warnke, I.; Le, A.; Furche, F. At What Size Do Neutral Gold Clusters Turn Three-Dimensional? J. Phys. Chem. C 2014, 118, 29370-29377.

(94) Ferrighi, L.; Hammer, B.; Madsen, G. K. H. 2D-3D Transition for Cationic and Anionic Gold Clusters: A Kinetic Energy Density Functional Study. J. Am. Chem. Soc. 2009, 131, 10605-10609. 